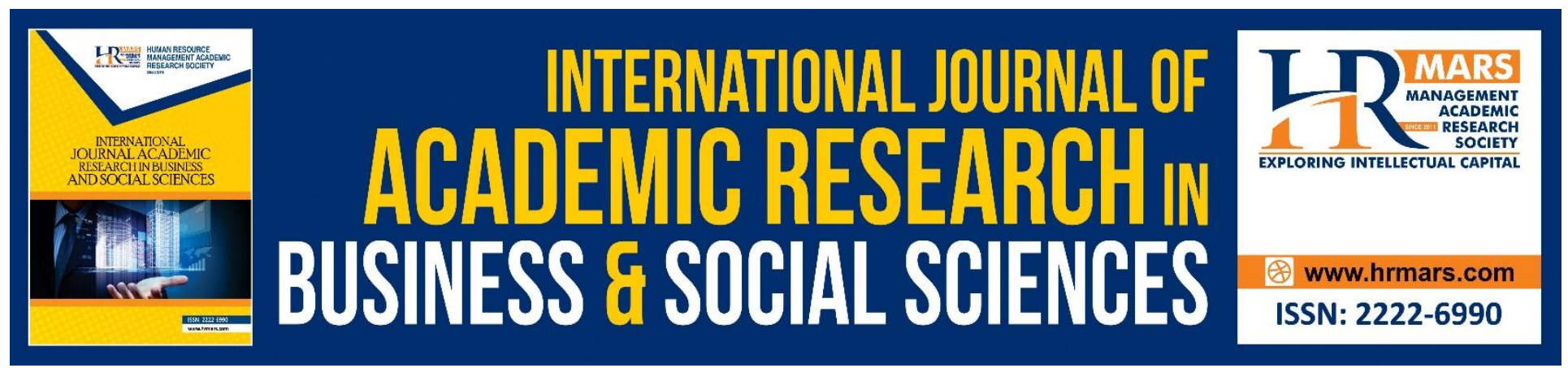

\title{
Exploring the Role of Training Abroad Programs for Department Head Managers of International Hotel Chains in Jordan: Perceptions and Attitudes
}

Mousa Masadeh, Fawwaz Alhammad, Mukhles M. A. Al-Ababneh, Samer AlSabi

To Link this Article: http://dx.doi.org/10.6007/IJARBSS/v10-i6/7384

DOI:10.6007/IJARBSS/v10-i6/7384

Received: 02 April 2020, Revised: 22 May 2020, Accepted: 09 June 2020

Published Online: 24 June 2020

In-Text Citation: (Masadeh et al., 2020)

To Cite this Article: Masadeh, M., Alhammad, F., Al-Ababneh, M. M. A., \& Al-Sabi, S. (2020). Exploring the Role of Training Abroad Programs for Department Head Managers of International Hotel Chains in Jordan:

Perceptions and Attitudes. International Journal of Academic Research in Business and Social Sciences, 10(6), 872-891.

Copyright: (c) 2020 The Author(s)

Published by Human Resource Management Academic Research Society (www.hrmars.com)

This article is published under the Creative Commons Attribution (CC BY 4.0) license. Anyone may reproduce, distribute, translate and create derivative works of this article (for both commercial and non-commercial purposes), subject to full attribution to the original publication and authors. The full terms of this license may be seen at: http://creativecommons.org/licences/by/4.0/legalcode

Vol. 10, No. 6, 2020, Pg. 872 - 891

Full Terms \& Conditions of access and use can be found at http://hrmars.com/index.php/pages/detail/publication-ethics 


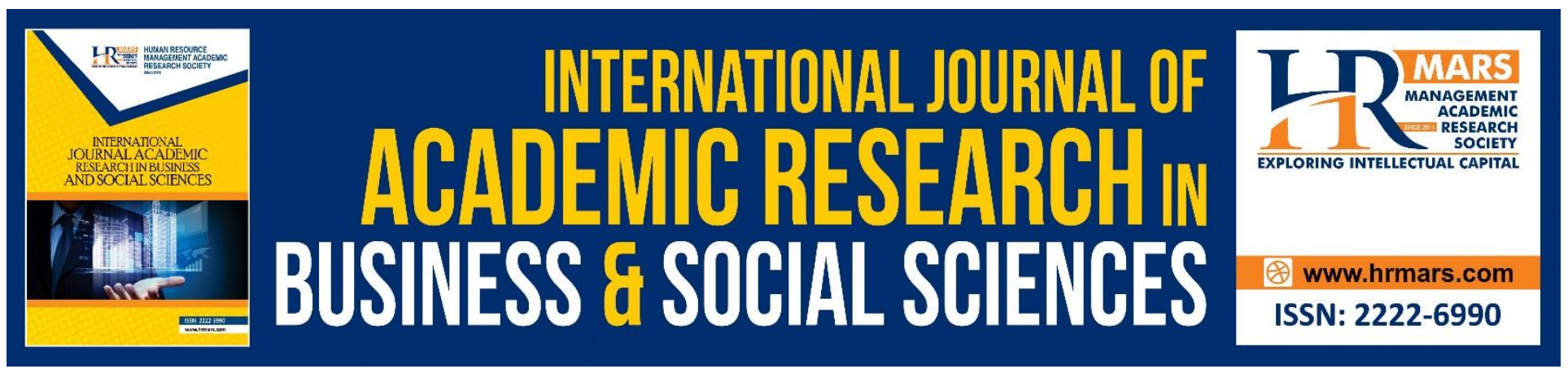

\title{
Exploring the Role of Training Abroad Programs for Department Head Managers of International Hotel Chains in Jordan: Perceptions and Attitudes
}

\author{
Dr. Mousa Masadeh \\ Petra College for Tourism and Archaeology, Al-Hussein Bin Talal, University, Petra, Jordan \\ Email: jordantourism@hotmail.com \\ Dr. Fawwaz Alhammad \\ Amman University College for Financial \& Managerial Sciences, \\ I-Balqa Applied University- Amman-Jordan \\ Email: dr.falhammad@bau.edu.jo \\ Mukhles M. A. Al-Ababneh, Dr. Samer Al-Sabi \\ Petra College for Tourism and Archaeology, Al-Hussein Bin \\ Talal University, Petra, Jordan \\ Email: mukhles.ababneh@gmail.com, sa.alsabi@gmail.com
}

\begin{abstract}
(IHCS) dominate the hotel industry around the world, including in Jordan. While considerable research has been conducted to evaluate the impact of employee training in a wide range of industries, research in the area of human resources training in the hotel industry is lagging behind. In Jordan, general managers in IHCs are often expatriate individuals. This research aimed to identify the value of 'training abroad' for local department heads of IHCS. In addition to a literature review on this topic, focus groups with a representative group of 24 IHC department heads, were conducted to discuss the current context of 'training abroad' programs in IHCs in Jordan and gain a better understanding of the perceptions, barriers and benefits of these programs. Five major themes were identified which reflected issues, ideas and attitudes of department heads towards 'training abroad'. Overall, it seems that department heads support 'training abroad' and they view it as a necessary and important component for their own success but also the success of the hotel overall. The participants identified important components of a 'training abroad' program such as being specific for certain job aspects but also generic enough so that participants can learn about various aspects of the hotel business. Criteria that play a role in the selection process of candidates for this training, include among others, work experience, confidence and ambition to develop further in their career, reliability, and management support. Perceived barriers to 'training abroad' for IHC department
\end{abstract}


heads in Jordan include existing culture, cost of training, family commitments and company reluctance to support such training. Participants discussed benefits of personal and professional growth as a result of the 'training abroad' experience. Ultimately, improved leadership at the hotel could lead to improved services and better business and profit for the hotel. This study provided an important insight into the area of human resource training for IHC managerial staff in Jordan. This information will guide the development of more empirical research on this topic but it may also have practical implications human resource management practices in IHCs in Jordan.

Keywords: Training Abroad, Department Heads, Human Resources, Perceptions, Attitude, International Hotel Chains.

\section{Introduction}

Providing training for the development of the human resources of any organization is deemed as an investment since the success of the organization depends on the success of its human resources (Hope, 2004; Hoque, 1999; Price, 1994; Masadeh, 2012c).

Ladkin and Juwaheer (2000) argue that international hotel chains (IHCS), which have branches around the world, need to place more emphasis on training abroad, especially for hotel managers in developing countries. As many developing countries do not have the structure or resources to train hotel staff in their own country, training abroad will provide the IHC personnel with the opportunity to learn new techniques and "best practices" which they can then apply in their own hotel.

Masadeh (2013b) examined training practices in IHCS as well as middle-management attitudes towards out-of-country training. This research shed light into this little-researched field and revealed middle-managers' overwhelming support for this type of training but also revealed some barriers, including lack of company support.

When it comes to training for IHC personnel, it is emphasized that that more attention should also be paid to the training and development of heads of departments in high-quality hotels, given their major role and increased responsibilities in the organization (Ramos, Rey-Maquieira, and Tugores, 2004; Zhang, Lam and Bauer, 2001; Timo and Davidson, 2005; Masadeh, 2009). Notably, in IHCs, foreign staff occupy the highest positions as far as management and supervision are concerned (Hope, 2004). These expatriate staff members are paid approximately triple or quadruple the amount of what the indigenous staff are paid (Webb and Wright, 1996). In spite of IHCs having resources to employ foreign managers, there is relatively little previous research suggesting the replacement of these costly managerial resources with as capable indigenous resources (Barber and Pittaway, 2000; Leiba O'Sullivan, Appelbaum and Abikhzer, 2002).

To date, limited research has been conducted to examine the possibility of carrying out training programmes abroad for department heads within IHCs. More specifically, no such research has been conducted for IHC department heads in Jordan. This research aims to build on earlier research by Masadeh (2013b) and explore perceptions, attitudes and barriers towards 'training abroad' for ICH department heads in Jordan.

\section{Literature Review}

Although considerable research has focused on training in business studies, little research has been done in the area of training in the hospitality industry (Ingram, 2000). Hotels and restaurants have been the centre of attention of the research that has been conducted (Barrows, 2000) and in addition, consumers rather than the employees have been the main focus (Ingram, 1997). 
McGunnigle and Jameson (2000) argued that more research should be done to understand management practices in hotels. Avcikurt (2003) emphasized the importance of training for hotel managers to improve their skills, knowledge, behaviours, self-esteem and communication, and argued that the absence of training resulted in them being inefficient, in addition to lowering their self-confidence. These latter two points are also supported in earlier research by Burgess (1994) and Okumus and Hemmington (1998) who suggested that more research should be done into all levels of management, so as to get to the heart of management practices in hotels.

Organizations started taking an interest in developing their managers in the mid-1980s (Garavan, 1997), alongside the appearance of the concept of strategic human resource management (HRM) in this period (Biswas and Cassell, 1996). Companies realized that human resources need to be managed strategically as this will help them gain a sustainable competitive advantage over rivals in an extremely competitive market (Khatri, 1999).

Garavan (1997) had identified the need for training programmes related to management in chain hotels and had reported that training programs were necessary for adapting to future needs since managerial work calls for training for specific requirements. However, in the literature, little attention has been paid to training programmes for management staff in IHCs. This is particularly true for managers at the level of department heads in IHCs.

According to Ramos, Rey-Maquieira, and Tugores (2004), there is a large demand for head departments' training in high-quality hotels. In a survey with a wide sample (Ramos, Rey-Maquieira and Tugores, 2004), it was also found that more training requirements are needed for heads of departments of hotels despite that fact that, among all of the individuals surveyed, employees with greater job responsibility (e.g. managers) receive a much greater share of the training provided by the hotels. Based on survey conducted by Zhang, Lam and Bauer (2001), the need to pay more heed to training head departments in hotels was also emphasized and Timo and Davidson (2005) who examined the views of managers towards training, found an overall significant positive response advocating about the need for more training for them.

'Training abroad' has been identified as an important aspect of management development for IHCS in developing countries (Ladkin and Juwaheer, 2000; Masadeh, 2009; Masadeh, 2013a, Masadeh, 2013c). This is especially important as many countries do not have the structures to train hotel staff locally. 'Training abroad' can support managers in developing countries learn new techniques and "best practices" that they can apply to their job. In addition, this knowledge can be used to train others at the hotel as well as for professional promotion of these managers within the hotel hierarchy (Masadeh, 2009; Masadeh, 2013b).

In IHCs, often foreign staff occupy the highest positions as far as management and supervision are concerned (Hope, 2004). In these cases, the expatriate managerial staff are paid approximately triple or quadruple what the indigenous staff are paid (Webb and Wright, 1996). Employing foreign managerial human resources is costly, relatively complex, resulting in a negative economic impact on the company and is fraught by many barriers and problems (Barber and Pittaway, 2000; Leiba O'Sullivan, Appelbaum and Abikhzer, 2002). In spite of this, there is relatively little previous research suggesting the possibility of replacing these people by capable indigenous resources.

\section{Methodology}

Existing theories and models of training based on the literature review were used in order to identify the main variables and issues related with training in general as well as 'training abroad'. The 
approach taken in this research is inductive in nature because we could not predetermine or define the variables in advance.

It was decided that qualitative research would be carried out, as it gives valuable results and is strongly recommended in research related to the hospitality industry (Ingram, 2000; McGunnigle and Jameson, 2000; Buick and Thomas, 2001; Masadeh et al., 2016). Focus groups were chosen as one approach for data collection as they allow the researcher to "drill" more deeply to attain in-depth insights into the researched topic (Barrows, 2000, Masadeh, 2012a), and collect a certain amount of information (Krueger, 1994; Gibbs, 1997; Barrows, 2000) and opinions (Hines, 2000) from a small number of people in a short time. The focus group approach is commonly used in the literature (see, for example, Lankshear, 1993; Hoppe et al., 1995; Laflin and Hyatt, 1999; Nassar-McMillan \& Borders, 1999; Mcneill, Sanders and Civille, 2000; Trocki, 2000; Nassar-McMillian and Borders, 2002; Prince and Davies, 2003; Constantine and Bourne, 2005; Kim et al., 2005; Deshpande, 2007; Tracey and Barham, 2007). The setting for this study was all IHCs in Jordan in the four main tourist cities in Jordan (Amman, Petra, Aqaba, Dead Sea), which contain all of Jordan's IHCs.

\section{Purpose of Focus Groups}

The focus groups were exploratory in nature and their goal was to gain a better understanding of the attitude of department heads with respect to 'training abroad' This approach usually produces useful information (Threlfall, 1999), particularly in the absence of research on specific topics or when the topic has been minimally researched (Nassar-McMillian and Borders, 2002; Masadeh, 2012b). This approach is also helpful in identifying survey items (Morgan, 1997). This approach is the most common type of focus group ahead of "clinical focus groups" and "phenomenological interactioncentred focus groups" (Hines, 2000: 10).

\section{Number of focus groups}

According to Evmorfopoulou (2007), there is no rigid rule about how many focus groups are enough to collect the needed information. For this study, four focus groups were convened in meeting rooms in three different places, in "compliance" with one of the copious "rules" as reported by Krueger (1994) who supports that focus groups research should comprise a minimum of three focus groups. The focus groups consisted of a purposeful sample (one department head randomly selected from each hotel chain) of a total of $24(n=24)$ department heads participating from ICHs in Jordan.

\section{Composition of Focus Groups}

In the literature, there are mixed perspectives in respect to the ideal number of participants that should join the focus group. While focus group composition ranges greatly (Morgan, 1988; Ruyter, 1996; Prince and Davies, 2001; Leitao and Vergueiro, 2000, Evmorfopoulou, 2007; Marczak and Sewell, 2007) most often, groups are composed of approximately 8 respondents (Boddy, 2005). Some researchers, however, have conducted focus groups that involve 10 to 23 participants (Braithwaite et al., 2004), and one study even had 31 participants in one focus group (Gloet, 2002). It has been noted that eight to 12 participants is common practice in the USA (Falco et al., 1998 cited in Prince and Davies, 2001), while 5 or 6 is widely utilized in the UK and other countries (Marketing News, 1995 cited in Prince and Davies, 2001).

Dreachslin (1999) points out that large focus groups may produce wide-ranging ideas, but may produce a competitive environment for the vocal and dominant members when they expect that 
focus group discussion must be completed within a specified time frame. Additionally, larger focus groups would be difficult for a facilitator who is new and has little experience in running focus groups. Dreachslin, Jinks and Daniels (1999) found that having a larger group was difficult to control and more difficult for achieving achieving equal participation in the discussion.

Ruyter (1996) stated that, "middle-sized" groups provide the best results with respect to the quality of ideas and the satisfaction of group participants. However, the researcher has embraced the acknowledgment in Prince and Davies' (2001) research that "small-sized" groups of four to 6 may be more productive since they encourage members to partake in the discussion: consequently, a considerable amount of different ideas would be generated on the topic under discussion within a certain time limit.

Taking into account recommendations of previous research as well as the total number of freely granted consent of the hotels for the participation of their department heads, the researcher decided that each focus group would consist of six department heads. Three four group sessions involving a total of twenty four head departments from IHCs in Jordan scattered across the country ( $n=6$ in each group) were conducted.

\section{Format for Focus Groups}

Open discussion, guided by a set of different questions (open-ended format), was the method used in conducting the three focus groups with 24 participants in order to explore ideas and attitudes of $\mathrm{ICH}$ department heads towards 'training abroad'. Overall, the interaction between the focus group members was effective, the researcher was able to "drill" deeply in the unexplored topic of "training abroad', and useful data was yielded and captured.

\section{Analysis}

Qualitative analysis of the focus group discussion results revealed a number of issues and ideas generated by participants within the focus groups. Content analysis was used to qualitatively analyze particiapnts' responses and main themes and recurrent items were counted based on the number of times/occurrences (frequency) within the data. Verbatim quotations from the interviewees were used in the majority of this analysis and results in order to "lend authenticity and texture" (Maxwell, Watson and Quail, 2004: 162) and to "bring the data to life" (Taylor-Powell and Renner, 2003: 5) Five major themes were identified (content analysis) from participant responses to the different questions guiding the group discussions. Some parts of the discussion were left out since they were not relevant to the subject. The five themes reflected issues, ideas and attitudes of department heads towards 'training abroad'. All of the items in the final analysis of focus groups were generated from the focus groups.

\section{Results}

\section{General Perceptions for 'Training Abroad'}

Department Heads (participants) Support 'Training Abroad'

When the recruited IHC department heads were asked about their view of 'training abroad', most of the participants embraced it and were excited about it. Some indicated that 'training abroad is "needed". Others expressed a desire to participate: "I wish I could get it", while some participants 
who had attended 'training abroad' in the past expressed their satisfaction with the program: "I went abroad for training and it was amazing".

Discussions revealed that most IHCS (19 out of 24 chains) are already offering 'training abroad' programs for their department heads. Such training courses may take place in other countries of the region (e..g. Dubai, Lebanon, Saudi Arabia) or in Europe and the USA.

One participant indicated that: "When one of hotel chains was inaugurated in Qatar, at least 4 managers from Jordan were sent for 3 months..."

Another participants said that: "I participated in two training sessions outside Jordan: our hotel is deemed one of the unique hotels to undertake this type of training, organized by the company management and done every now and then in certain countries"

In the focus group discussion, it was also indicated that in the past, department heads were sent outside of Jordan for training (e.g. USA, France or the UK) because in Jordan there was only one hotel chain. However, nowadays, as there are many hotel chains in Jordan, training takes place inside the country or in other countries of the Middle East region.

\section{Department Heads Emphasized the Importance and Necessity of 'Training Abroad'}

A common theme which surfaced repeatedly duirng the focus group discussions revolved around training in the country (in Jordan) versus training abroad. It was mentioned that training outside of the country is totally different compared with training inside the country: the hotel abroad is not the same as the one in Jordan despite belonging to the same chain, and, therefore, 'training abroad' will cover different aspects and will follow a different approach. The participants emphasized the importance of and necessity of 'training abroad':

"...the material in training outside of Jordan is unlimited and, whereas it is limited in Jordan and the ideas are restricted...unlike outside Jordan, people giving the training are not qualified whereas those who give the training outside Jordan are skilled and qualified enough to give the training."

However, based on data collected from the participating department heads, it seems that in many cases, the majority of training programs take place in contiguous regional Arab countries. For example, if an Italian restaurant is going to be inaugurated in a hotel, the company ought to send its chef for training to the best Italian restaurant in the Middle East, found in Dubai.

As it was pointed out, training in regional Arab countries bears close resemblance to the training inside Jordan. On the other hand, they recognized that western countries are entirely different in terms of culture, language, business approach and training frame. As such, most participants did not feel that they have much to gain in knowledge if the training is held in another Arab country.

A few participants, however, expressed that regardless of the location of the training, what matters most is the right type of training.

\section{IHCs can Afford 'Training Abroad'}

In all three focus group sessions, the department heads indicated that the hotel chains make revenues high enough so that they can afford 'training abroad' and therefore they should plan for offering it to their managers.

One suggestion from focus group participants was: "... a certain budget should be set for it." Another said that: "...a certain budget is fixed for annual training"

On this topic, several participants also pointed many hotel department heads, especially for luxury hotels, are expatriates. These individuals not only find it hard to communicate with the hotel 
employees but they also get paid large sums of money by the hotels to cover additional expenses (e.g. plane tickets, residence and school tuition fees for their children). The participants noted that in contrast, it would not be too costly to hire local department heads (local staff get paid a quarter of the salary of the expatriates' salary) and in addition the local managers would be able to form stronger relationships with the local hotel staff.

Another participant indicated that local managers and expatriates could co-exist successfully on the job:

"Let's assume the Marriott does not recruit native managers, and then it is complete failure. Not all the managers should be native though; there should be a variety of both cultures, which is a good way of learning each other's"

\section{Barriers to 'training abroad' for IHC department heads The Cost of Training}

The most common barrier to 'training abroad' as mentioned by the participants is the cost of the training, which is discussed in the context of financial contstraints of the hotel but also of the trainees. For the hotels, costs usually include tickets and accommodation, which could be exorbitant when sending 3 or 4 persons for training. Moreover, expenses are generally high in foreign countries, especially in the United States and European countries. While participants recognized the increased cost of 'training abroad' and the fact that

"...the company has a certain budget for training to stick to", they also emphasized that the beneficial outcomes of 'training abroad' for the department heads and the hotel are more significant:

"...training abroad is more costly...but the beneficial outcome is more."

"When sending talented and gifted managers for training abroad, the hotel bears no loss regardless of how much the costs are."

Others also commented that if the training takes place in a hotel of the same chain, the hotel will incur only minor costs.

During this discussion, it was acknowledged that even though the hotel covers most expenses, the trainees also need to pay for expenses.

".outstanding but unaffordable".

Two participants who had participated in 'training abroad' in the past, indicated that they were personally able to afford going abroad, and three other participants said as well that they could afford paying for the training themselves.

\section{Wasta and Mahsoubiah Practices}

Wasta and Mahsoubiah are Arabic terms for 'nepotism' or 'favouritism'. Even though no previous research has been done on nepotism or favouritism in the hotel work environment in Jordan, according to the views of participants in this research, these practices exist in the recruitment and promotion process, as well as in training programs, particularly those conducted abroad (Masadeg, 2009; Masadeh, forthcoming). There was general agreement among all the participants that Wasta and Mahsoubiah are barriers to 'training abroad'.

One participant commented on this by saying:

"You have no big Wasta, how you would be selected"

Several participants reported that some individuals are chosen for these programs only because they are friends or relatives of those who make decisions on the candidates for the out of country training. 
INTERNATIONAL JOURNAL OF ACADEMIC RESEARCH IN BUSINESS AND SOCIAL SCIENCES

Vol. 10, No. 6, June, 2020, E-ISSN: 2222-6990 @ 2020 HRMARS

Some participants also expressed contempt that worthy candidates may not get the opportunity to attend 'training abroad' because of these practices:

"...so they opted for another one for a change, despite the fact I was the most worthy of it. This was blatantly unfair"

"How we would know when one had already been chosen even the tickets were already booked for him... this is utterly unfair."

\section{Company Reluctance to Support 'Training Abroad'}

In the opinion of the group, it was mentioned that 'training abroad' is somewhat discouraged by the company because of past experiences with unsuccessful training outcomes:

"...hotels are not keen on sending managers and supervisors for training abroad because they fail most of the time."

"Throughout my experience, many persons sent for training abroad failed in their mission. Therefore, hotels are reluctant to undertake training abroad and consider putting of the idea."

One participant said that there is also fear of the unknown due to the political instability of the region :

"Companies do not like to spend a considerable amount of money on management development; they are concerned about the political situation... you never know what tomorrow will bring in this unstable region."

Another example of a political barrier is visa procedures. There have been cases where visa applications for trainee candidates in Jordan have been refused by the embassy.

\section{Language Reasons}

One of the most frequently reported barriers for 'training abroad', as cited by the participants, is language. Without good knowledge of another language, it is difficult to attend and learn from 'training abroad'. For this reason, some companies opt to offer training in another country of the region:

"The language is no longer a hindrance for training in Arab countries, for the language is the same." Family reasons

Being away from their family for training is reported as a barrier to 'training abroad'. Sometimes, 'training abroad' may require that the trainee is away for several weeks. So, before undertaking 'training abroad', some department heads have to spend a great deal of time contemplating this decision.

Females were under-represented in the group; just one female department head participated. The facilitator managed to draw her out after noticing that she was quiet, shy and not expressing herself in a predominantly male focus group. She reported:

"Women are not accustomed to travelling, as there is rejection on behalf of the family of training abroad due to her upbringing. This has been there for many years due to social, cultural and religious factors and particularly the Islamic religion...personally, I support training abroad: I am certain there are other girls who share my point of view" 


\section{Contractual Reasons}

It was cited in the focus groups discussions that there are many cases where department heads, after having completed their 'training abroad', resign from the hotel. To address this issue, some hotels have started implementing a contract regulation, where department heads sign contracts agreeing to work for a specified period of time at the hotel, so that there will be no loss in efforts or costs. In the case where a department head resigned, they would be obligated to pay all the costs of this training according to the contract signed between both parties concerned.

Participants had an ambivalent attitude toward these contracts and some of them viewed this agreement as a barrier to attending 'training abroad':

"...this makes people think twice before agreeing to take training abroad..."

\section{Selection Criteria}

In the focus group discussions, it was evident that there were certain factors that were perceived to be essential for the selection of any department head to participate in 'training abroad'.

Language knowledge

Language knowledge was mentioned as an important criterion for 'training abroad' candidates. Some participants expressed that poor language skills can affect their learning experience and confidence during the training.

"I think language is vital for anyone to be selected for training abroad"

Qualifications, experience, and reliability

During the discussion, participants debated whether higher education (e.g. a university degree) should be one of the selection criteria. While some participants supported that, others felt that other qualifications, such as work experience, were more important to be considered.

But overall, participants agreed that the "right person" has to attend the 'training abroad':

"To undergo this training, the right person should be well chosen: for example, last year, the hotel sent somebody for an training abroad training but he failed. He was the wrong, unqualified trainee."

"...instead of sending 5 trainees, we could send one qualified and eligible person"

The participants of the focus groups were of different ages, and while some argued that younger managers should be preferred for training given that they are at the beginning of their career and have "high potential", others supported that "suitable candidates" should be selected regardless of age.

Suitable candidates would be reliable managers "...who can be depended on to accomplish the training successfully."

Open-mindedness, confidence, and ambition

Open-mindedness was discussed as one characteristic that a training candidate should have in order to succeed. According to the participants, an open-minded person would be able to socialize in a new and foreign environment and this would contribute to a more successful training experience.

"...so l'd say for myself, a candidate should be open-minded enough to listen to or take an interest in other countries' cultures and to socialize, especially when the training is in any of the Western countries."

The importance of pesonality strength, confidence and ambition were also emphasized as important traits when choosing department heads to take training abroad: 
INTERNATIONAL JOURNAL OF ACADEMIC RESEARCH IN BUSINESS AND SOCIAL SCIENCES Vol. 10, No. 6, June, 2020, E-ISSN: 2222-6990 @ 2020 HRMARS

"I know a manager who underwent a 5-day training where he did not demonstrate any participation nor debate due to lack of self-confidence... because his self-confidence was not strong enough this resulted in bad participation... and he told me after it he came back he did not enjoy it, so I doubt it if he would live through this experience again"

In terms of ambition, one participant, said:

"It must be an ambitious manager who is eager and looking to progress and further his career" Another noted:

"...at the beginning, there were 11 department heads:, only 9 managed to get through., The reason the other $\mathbf{2}$ withdrew was the arduousness of the course and lack of ambition for the future"

\section{Gender}

Interestingly, the facilitator noticed that participants in focus groups sessions were referring to "he" in their statements (For example: See quotations). This indicates that men are usually preferred for 'training abroad' opportunities. A possible explanation for this may be the fact that women do not usually hold department head positions in IHCs.

In fact, there was only one female participant in the focus groups. She commented that that it is difficult for women to travel abroad due "...rejection on behalf of the family of training abroad..."

\section{Management Support}

Feedback during focus group interviews indicated that support from upper management is paramount (15 responses) for being selected to go to 'training abroad'. And the interviewees feel that top management, especially, expatriate managers, usually support 'training abroad'.

Nature of Training

Members of the focus groups discussed the following aspects for 'training abroad':

To be conducted in both the company hotel and other venues

Some participants stated that training should be conducted only within the company's business environment. One participant, for example, said:

"To me training should be conducted within the hotel"

Other participants, however, noted that there are other valuable training components such as seminars and conferences and for this reason 'training abroad' should not only be conducted in hotels. One participant who had attended 'training abroad' indicated that:

"...not only did the training program take place in one hotel, it took place in many hotels of the same chain in Dubai: as well, we attended seminars, external lectures about hotels in places away from the hotel"

\section{To be both job-specific and Generic}

According to some members of the group, training programs should be tailored to be specific for the department that the trainees are heading. This way, they can focus on acquiring more specialised skills regarding their job, which in turn will enable the trainees to improve his or her work back home. Other participants, however, noted that training should be generic in nature rather than specific in order to explore the practices of others in other hotels' departments where he or she will be trained. 
INTERNATIONAL JOURNAL OF ACADEMIC RESEARCH IN BUSINESS AND SOCIAL SCIENCES

Vol. 10, No. 6, June, 2020, E-ISSN: 2222-6990 @ 2020 HRMARS

This would help to "...have a clear picture of how hotels from the same chain are managed and work..." as one participant explained.

Another member described it:

"...by this I mean the manager can be transferred from one section to the other in order to learn how other departments work in other hotels..."

Other participants stated that some portion of such training should be about specific areas (his main job) but also generic (all aspects of the hotel business). For example, one respondent indicated that: "...along with training about the same work he or she does, also there should be diversity in training and there should be comprehensive training as far as hotel management, hotel services, are concerned."

Benefits of Training abroad to managers and their hotels

Focus group discussions revealed the benefits of training abroad. These include:

Improvement of language skills

Participants in all three focus group sessions highlighted that 'training abroad' contributes to improving their language skills.

Increase in knowledge and development of new skills

Participants discussed the value of 'training abroad' in terms of being exposed to a different mentality, culture and perspectives. They mentioned that through their interactions with other trainees in a different country they expected that their knowledge and skills for their job would expand.

One participant spoke about a course abroad and the value in expanding his knowledge of the hotel business:

"...had a part of such an interesting training, expanded my knowledge of the hotel business"

It was noted in group discussions that 'training abroad' can offer a fund of ideas to the participants since they are in a different environment, come in contact with other participants from different hotels and departments, and this will help them to enhance the creativity and innovation in their own business:

"I went to Egypt for training: I pointed out that breakfast was served on the same floor as my room. This was a new idea that was not available in my hotel and which I attempted to suggest..."

The overwhelming majority of participants argued that new skills of all kinds required by the job are likely to be learned by participating in 'training abroad', so that they are able to advance their careers. "...I'm sure I will learn new skills during training abroad to take things forward" a member said.

It was also indicated that by participating in training abroad this would help develop their leadership skills in various areas. One participant who had been on training abroad in the past said:

"I participated in training abroad as this would help me upgrade my skills...it has been extremely useful and my managerial skills really developed, particularly with regard to my department."

Learning more about technology and increased work efficiency

The focus group members indicated that because Jordan is a developing country, there is a lack of technological breakthroughs in the hotel industry. Therefore, they believe that:

"... when being trained outside the country, and I mean not in the Arab countries, the trainee will learn new technologies in order to become proficient in their job." 
One participant indicated that training abroad helps them to learn more about technology, so that he can master the new and recent material and equipment. This will save him time and thus dramatically increase his work efficiency (by completing more tasks in less time).

Improvement in work motivation

Based on participants' responses, the belief is that their motivation for their work will be enhanced after 'training abroad' because they will come back to their hotels wanting to show that they have become better at their jobs.

One member who had participated before in training abroad said:

"...after the training, I came back motivated to work as hard as I could to improve my department..."

\section{Increased self-confidence and Personal Sense of Achievement}

Participants' responses indicated that training abroad not only would help them develop their skills further and gain new knowledge but it would also help them with their self-confidence, inreasing their faith in their own abilities.

"... I pointed out that trainees having their training for the first time outside Jordan happen to be on their own: they do not tend to participate in the training for fear of making mistakes. However, they reap the benefits when they come back from training. Confidence will be increased, especially a person who has done more than one training course has a stronger self-confidence." one participant said. One member who participated in training abroad indicated that he was already experienced, and was rewarded by a personal sense of achievement of having been part of such training, noting:

"...I did enjoy that training and it has given me a feeling of a personal sense of achievement." Increased security of employment

Security of employment was perceived as another benefit of participation in the 'training abroad' programmes, particularly the longer ones. The participants recognise that 'training abroad' plays a role in reducing the risk of job losses when signing contracts by both parties towards maintaining the security of employment wherever possible:

"...given the funding injected for such training, hotels cannot easily give up on their managers" one member said.

"...this contract creates commitment as far as the managers and hotels are concerned" said another participant.

Increased possibilities for promotion opportunities to higher positions and improved earning potential

It was claimed that a training program would provide participants with additional advantages such as qualifications that could help them climb the ladder within their company for higher-level potential positions.

It was indicated that when a staff member is promoted to a position of increased responsibility it results in a higher pay grade maximum, thus, as one participant noted 'training abroad' was viewed as an opportunity that: "... would help on my way to have a better future.

Learning about the cultures of customers and improvement of service quality

Training abroad helps participants know about others' ways of life, which will help them in their professional and personal life, so that when customers come over to hotels in Jordan, their needs can be understood. 
INTERNATIONAL JOURNAL OF ACADEMIC RESEARCH IN BUSINESS AND SOCIAL SCIENCES

Vol. 10, No. 6, June, 2020, E-ISSN: 2222-6990 @ 2020 HRMARS

"I will also gain insight into dealing with people on both a professional and personal level... for example, should there be a training course in England, when an Englishperson comes in, I can figure out how to deal with him."

Having discussed the advantages and benefits of training abroad, the participants noted that the training would contribute to improvements in the quality of the service provided for the customers, which is the ultimate goal of this training. As one explained:

"...plus the fact that dealing with these societies helps us know their traditions and customs. This advantage could be rather personal but could be transferred conveniently to our work"

Improvement of standards of training of the hotel

Participants believe that investing in 'training abroad' represents an opportunity for improving the standards of training at the hotel. Participants felt that 'training abroad' will enable them to share good practices that they have learned with other hotels from the same chain, with departmental colleagues and/or within their hotel, so that opportunities for colleagues' development are maximised:

"...the managers can reveal this experience to 2 or 3 people"

"...not forgetting, of course, when the training abroad is finished, we, are required to make better those who are inferior to us in terms of conveying new ideas and information to them."

It was also cited that in an effort to improve standards of training, some hotels undertake training in Europe and USA. Upon return, trainees can apply what they have learned to their job in Jordan and this can provide a high level of training consistent with an international hotel's requirements.

Increase in commitment and loyalty to the hotel and reduction in staff turnover rate

It was revealed by participants that this training will play a role in encouraging the department heads be committed and loyal to their organisations. As people see that the company is committed to developing its staff and is investing in such opportunities, the likelihood of staff quiting and leaving the organization is less. It was said:

"...both parties sign a contract which guarantees the manager's commitment"

"... the more the company invest in me the more I am loyal"

Contribution to the success of the company and improvement of hotel profitability

Participants expressed the view that implementing such training seems to help in the success of the company overall, including its profitablity, noting:

"Our company does a good job to train its managers either here or abroad, and this surely will ultimately reflect on managers to perform at the level needed to make our hotel successful in the market."

Participants discussed that the ultimate beneficiary of the training of department heads is the hotel as improved customer service due to the training will result in increasing customers and therefore, increased revenues for the hotel.

\section{Improvement in Hotel Safety}

On November 9, 2005, terrorists attacked three American chain hotels located in Jordan's capital, Amman - the Radisson SAS Hotel, the Days Inn and Grand Hyatt Hotel - and killed 60 people and injured 115 others. Participants indicated that after these terrorist bomb attacks, hotels have been 
required to provide extra security so that they ensure that guests have a safe and secure stay. 'Training abroad' includes training in technological equipment (e.g. specialized security equipment) and security budgets. This training is necessary and valuable since Jordan as a developing country lacked such expertise and equipment.

\section{Discussion}

The study aimed to provide a better understanding of the current context for out-of-country training in IHCS in Jordan and related barriers. As only limited empirical research has been conducted concerning training abroad for IHC management to date (Masadeh, 2009; Masadeh, 2013a, Masadeh, 2013b), this research aimed to add to existing empirical research on this topic by examining perceptions, attitudes, and barriers related to 'training abroad' for department heads of IHCs in Jordan.

A review of the existing theories and models of human resource management and human resource development in hospitality and hotel industry was undertaken to examine current opinion about training in the hotel industry. The overall findings from this review demonstrate the limited research available in the area of training for the hospitality industry and the need for research into training in hospitality especially since the hospitality industry offers a fertile area for investigation (Litteljohn, 1997; Barrows, 2000; Timo and Davidson, 2005; Masadeh, 2013c; Masadeh et la. 2016). Several studies emphasized the importance of 'training abroad' for department heads of hotels as this training will equip them with much needed new techniques and international "best practices" which they can then apply in their own hotel (Ramos, Rey-Maquieira, and Tugores, 2004; Ladkin and Juwaheer, 2000; Zhang, Lam and Bauer; 2001; Timo and Davidson, 2005). Previous studies have also reported an overall support for this training by the managers (Ramos, Rey-Maquieira and Tugores, 2004; Masadeh, 2009; Masadeh, 2013b).

In the absence of research examining the perceptions of department heads in IHCs towards 'training abroad', focus group discussions provided a springboard for obtaining much useful information with respect to out- of- country training (Nassar-McMillian and Borders, 2002). The aim of the focus groups was to gather sufficient information about attitudes of IHCs department heads towards 'training abroad'.

Even though, none of the participants had heard of the focus group approach before, most of them reported that it was a 'rewarding experience' and a "good opportunity'. The focus group approach was appropriate for this research (Barrows, 2000; Krueger, 1994; Gibbs, 1997; Hines, 2000) as it allowed for effective interaction between groups members and allowed the researcher to "drill" deeply into the subject under discussion, capturing useful data.

Discussions with department heads from Jordan's IHCs revealed important information around perceptions and attitudes towards 'training abroad' programs for hotel management staff. Five key themes emerged from the interviews data. Participants shared their perceptions on 'training abroad', their views on how the selection process works for this training, perceived barriers, the components that this training should include according to their views, and perceived benefits of 'training abroad' for the participants but also for the hotel. 
Overall, it seems that department heads support and would like to participate in 'training abroad'. They feel that it is a necessary and important component for the success in their role and the success of the hotel overall. This is consistent with findings by Masadeh (2009) and Masadeh (2013b) who also reported support and enthusiasm by middle managers at IHCs in Jordan for such programs but also with previous research reporting that managers view this type of training as an indespensable investment for the hotel (Smith, 2002). Department heads mentioned that this is a practice that IHCS already use and can afford to offer to their managerial staff. Therefore, the reported support by the managerial staff emphasizes the need for IHCs to prioritize this type of training.

The participants identified important components that a 'training abroad' program should inlcude such as being specific for certain jobs in the hotel but also generic enough so that participants can learn about various aspects of the hotel business. Participants also emphasized the importance of having the training in a venue outside of a hotel environment. Masadeh (20009) and Masadeh (2013b) had reported that managers supported a broader and more comprehensive training as this would allow them to explore practices of other hotels and other departments.

Despite of the option for attending 'training abroad', participants expressed that not all department heads may be ready or qualified to be part of such a program. They discussed the criteria that they perceive are used for the selection of candidates for this training. These include among others, qualifications and experience, confidence and ambition to evolve in their career, reliability, and management support. These are in line with Masadeh's (2013b) findings and can be used to guide selection policies in the ICHs.

Participants listed a number of perceived barriers for being part in 'training abroad'. The barriers focused on existing cultural practices in Jordan (e.g. Wasta and Mahsoubiah), cost of training, which may be high for the company but also for the participants, family commitments (especially when the 'training abroad is long), company reluctance to support such training for a number of reasons including political instability in the region or due to specific contractual agreements between the hotel and the employee. These barriers have been reported in earlier research (Masadeh, 2009; Masadeh, 2013b) and explain hesitation for 'training abroad' as well as provide a number of considerations for potential trainees as well as hotels to take into account when planning for 'training abroad' programs.

On the other hand, the participants listed many benefits of 'training abroad'. These benefits relate to their personal and professional growth as well as increased loyalty towards the hotel that supported their training. In addition, the department heads who participated in this study also recognized the benefits that the hotel will enjoy after the staff are trained abroad successfully. Ultimately, employee satisfaction, especially at that level of a department head, translates to improved services and better business and profit for the hotel.

This study provided significant context around the topic of 'training abroad' for department heads of IHCs in Jordan. This information filled important gaps in this area. Moreover, it offers valuable information for ICHs to consider as guidance when planning 'training abroad' programs for their managerial leads.

\section{Conclusion}

This research adds significant knowledge by filling a gap in the hotel industry literature by investigating training in IHCs, particularly out-of country training for department heads in these hotels in Jordan. Data from this research can be provided to researchers to further this research and 
practitioners of hotel management. It also may have practical implications for improving human resource management in IHCS in Jordan. The research supports that a successful 'training abroad' experience can benefit both the trainee and the hotel and could potentially offer the IHCs in Jordan the opportunity to employ more, well-qualified, local managers who would contribute to the hotel's success and efficiency.

This research contributes significant knowledge to the little researched area of training and development for management staff in the hotel industry. Moreover, this research aimed to address this topic for the hotel industry in Jordan, a Middle Eastern country, where despite being a main tourist destination, cultural and societal traditions may pose additional challenges for employees in the hospitality industry.

This study built on earlier research by Masadeh (2013) to address broader perspectives towards 'training abroad' as they relate to an even more specific group of managers, namely department heads for ICHs in Jordan. This is the first study focusing on this type of training for this group of managers in this industry.

The research employed a literature review but also an evidence-based focus group approach, which in addition to literature information provided rich empirical data on the topic. The study confirmed the feasibility and value of 'training abroad' programs for upper management IHC staff and suggests that consideration of such programs might contribute to hiring of more qualified local human resources. This study approach also yielded significant information to guide additional and more targeted research in this area of human resource training in the hotel industry, especially in developing countries. Practical considerations for such programs can also be extracted from this research which can be used by the hotel industry in Jordan currently.

\section{References}

Agut, S., Grau R., and Peiró, J. M. (2003), "Competency needs among managers from Spanish hotels and restaurants and their training demands", Hospitality Management, Vol. 22 No. 3, pp. 281295.

"Aiming at excellence at the Forte Hotel Group." (2002), Strategic Direction, Vol.18 No. 2, pp. 4-5.

Aktaş, A., Aksu, A. A., Ehtíyar, R., and Cengíz, A. (2001), "Audit of manpower research in the hospitality sector: an example from the Antalya region of Turkey", Managerial Auditing Journal, Vol.16 No. 9, pp. 530-535.

Alwahidi, J. (1990), The Workforce in Tourism Sector in Jordan. Unpublished Master thesis, University of Jordan.

Analoui, F. (1999), "Eight parameters of managerial effectiveness: A study of senior managers in Ghana", Journal of Management Development, Vol. 18 No. 4, pp. 362-390.

Antigua and Barbuda Bureau of Standards. (2008), "Smart Partnership: The Way Forward into the Millenium", available at: http://www.abbs.gov.ag [accessed 22 April 2012].

Baines, A. (1998), "Technology and tourism", Work Study, Vol. 47 No. 5, pp. 160-163.

Barber, N., and Pittaway, L. (2000), "Expatriate recruitment in South East Asia: dilemma or opportunity?", International Journal of Contemporary Hospitality Management, Vol. 12 No. 6, pp. 352-359.

Barrows, C. W. (2000), "An exploratory study of food and beverage training in private clubs", International Journal of Contemporary Hospitality Management Vol. 12 No. 3, pp. 190-197. 
INTERNATIONAL JOURNAL OF ACADEMIC RESEARCH IN BUSINESS AND SOCIAL SCIENCES

Vol. 10, No. 6, June, 2020, E-ISSN: 2222-6990 @ 2020 HRMARS

Baum, T., Amoah, V., and Spivack, S. (1997), "Policy dimensions of human resource management in the tourism and hospitality industries", International Journal of Contemporary Hospitality Management, Vol. 9 No. 5, pp. 221-229.

Birdir, K. (2002), "General manager turnover and root causes", International Journal of Contemporary Hospitality Management, Vol. 14 No. 1, pp. 43-47.

Carbery, R., Garavan, T. N., O'Brien, F., and McDonnell, J. (2003), "Predicting hotel managers' turnover cognitions", Journal of Managerial Psychology, Vol. 18 No. 7, pp. 649-679.

Conrady, R., and Buck, M. (2008), Trends and issues in global tourism, Springer, London.

Creelman, J. (1995), "Pay and performance drive human resource agendas", Management Development Review, Vol.8 No. 3, pp. 6-9.

Davies, D., Taylor, R., and Savery, L. (2001), "The role of appraisal, remuneration and training in improving staff relations in the Western Australian accommodation industry: a comparative study", Journal of European Industrial Training, Vol. 25 No.7, pp. 366-373.

Denham, N., Ackers, P., and Travers, C. (1997), "Doing yourself out of a job? How middle managers cope with empowerment?", Employee Relations, Vol. 19 No. 2, pp. 147-59.

Garavan, T. N., Heraty, N., and Barnicle, B. (1999), "Human resource development literature: current issues, priorities and dilemmas", Journal of European Industrial Training, Vol. 23 No. 4, pp. 169-179.

Garavan, T. N. (1997), "Training, development, education and learning: different or the same?", Journal of European Industrial Training, Vol. 21 No. 2, pp. 39-50.

Gibbs, A. (1997) "Focus groups", available at: http://www.soc.surrey.ac.uk/sru/SRU19.html [accessed 28 March 2012]

González, S. M. (2004), "Improving human resources management: some practical questions and answers", International Journal of Contemporary Hospitality Management, Vol. 16 No. 1, pp. 59-64.

Harris, K. J. (1995), "Training technology in the hospitality industry: a matter of effectiveness and efficiency", International Journal of Contemporary Hospitality Management, Vol. 7 No. 6, pp. 24-29.

Hines, T. (2000), "An evaluation of two qualitative methods (focus group interviews and cognitive maps) for conducting research into entrepreneurial decision making", Qualitative Market Research: An International Journal, Vol. 3 No.1, pp. 7-16.

Hope, C. A. (2004), "The impact of national culture on the transfer of 'best practice operations management' in hotels in St. Lucia", Tourism Management, Vol. 25 No. 1, pp. 45-59.

Huang, T. (2001), "The relation of training practices and organizational performance in small and medium size enterprises", Education + Training, Vol. 43 No. 8/9, pp. 437-444.

Hughey, A. W., and Mussnug, K. J. (1997), "Designing effective employee training programmes", Training for Quality, Vol. 5 No. 2, pp. 52-57.

Huyton, J. R., and Ingold, A. (1999), "A commentary by Chinese hotel workers on the value of vocational education", Journal of European Industrial Training, Vol. 23 No. 1, pp. 16-24.

Kaye, M., and Taylor, W. G. K. (1997), "Expatriate culture shock in China: a study in the Beijing hotel industry", Journal of Managerial Psychology, Vol. 12 No. 8, pp. 496-510.

Krueger, R. A. (1994), Focus Groups: A Practical Guide for Applied Research, Sage, Thousand Oaks, CA. Ladkin, A., and Juwaheer, T. D. (2000), "The career paths of hotel general managers in Mauritius", International Journal of Contemporary Hospitality Management, Vol. 12 No. 2, pp. 119-125. 
INTERNATIONAL JOURNAL OF ACADEMIC RESEARCH IN BUSINESS AND SOCIAL SCIENCES

Vol. 10, No. 6, June, 2020, E-ISSN: 2222-6990 @ 2020 HRMARS

Littrell, R. F. (2002), "Desirable leadership behaviours of multi-cultural managers in China", The Journal of Management Development, Vol. 21 No. 1, pp. 5-74.

Lockyer, C., and Scholarios, D. (2004), "Selecting hotel staff: why best practice does not always work", International Journal of Contemporary Hospitality Management, Vol. 16 No. 2, pp. 125-135.

Masadeh, M. (2009), Human Resources in international hotel chains in Jordan: "Out-of-country" training determinants. Unpublished PhD thesis. Coventry University.

Masadeh, M. (2012a), "Focus Group: Reviews and Practices", International Journal of Applied Science and Technology, Vol. 2 No. 10, pp. 63-68. ISSN: 2221-0997

Masadeh, M. (2012b), "Linking Philosophy, Methodology, and Methods: Toward Mixed Model Design in the Hostpitality Industry", European Journal of Social Sciences, Vol. 28 No. 3, pp. 128-137. ISSN: $1450-2267$

Masadeh, M. (2012c), "Training, Education, Development and Learning: what is the Difference", European Scientific Journal, Vol. 8 No. 10, pp. 62-68. ISSN: 1857-7881

Masadeh, M. (2013a), "Out-of-Country Training for Hotel Middle Managers in Jordan: Selection Criteria and Implications", European Journal of Tourism, Hospitality and Recreation, Vol. 4 No. 1, pp. 105-122. ISSN: 2182-4916

Masadeh, M. (2013b), “Perspectives on Foreign Training: Middle Managers in Jordan's International Hotel Chains", European Journal of Tourism Research, Vol. 6 No. 1, pp. 20-35. ISSN: 1994-7658

Masadeh, M. (2013c), "Women in the Hotel Industry: What's Missing from this Picture?", International Journal of Academic Research in Business and Social Sciences, Vol. 3 No. 1, pp. 573- 580. ISSN: 2222-6990

Masadeh, M., Al-Ababneh, M., Al-Sabi, S., and Bashar, M. (2016), "Focus Groups in Hospitality Research: Why are they not used in Jordan?", European Scientific Journal, Vol. 12 No. 20, pp. 359- 384. ISSN: 1857-7881

McColl-Kennedy, J. R., and White, T. (1997), "Service provider training programs at odds with customer requirements in five-star hotels", Journal of Services Marketing, Vol. 11 No. 4, pp. 249-264.

McGunnigle, P. J., and Jameson, S. M. (2000), "HRM in UK hotels: a focus on commitment", Employee Relations, Vol. 22 No. 4, pp. 403-422.

Nassar-McMillan, S. C., and Borders, L. D. (2002), "Use of Focus Groups in Survey Item Development." The Qualitative Report 7 (1). Available at: http://www.nova.edu/ssss/QR/QR7-1/nassar.html [accessed 20 July 2012]

O'Sullivan, S. L., Appelbaum, S. H., and Abikhzer, C. (2002), "Expatriate management 'best practices' in Canadian MNCs: a multiple case study", Career Development International, Vol. 7 No. 2, pp. 79-95.

Peacock, M. (1995), "A job well done": hospitality managers and success", International Journal of Contemporary Hospitality Management, Vol 7 No. 2, pp. 48-51.

Peters, M., and Buhalis, D. (2004), "Family hotel businesses: strategic planning and the need for education and training", Education + Training, Vol. 46 No. 8, pp. 406-415.

Pine, R., and Qi, P. (2004), "Barriers to hotel chain development in China", International Journal of Contemporary Hospitality Management, Vol. 16 No. 1, pp. 37-44.

Ramos, V., Rey-Maquieira, J., and Tugores, M. (2004), "The role of training in changing an economy specialising in tourism", International Journal of Manpower, Vol.25 No. 1, pp. 55-72. 
INTERNATIONAL JOURNAL OF ACADEMIC RESEARCH IN BUSINESS AND SOCIAL SCIENCES

Vol. 10, No. 6, June, 2020, E-ISSN: 2222-6990 @ 2020 HRMARS

Rowley, G., and Purcell, K. (2001), "As cooks go, she went: is labor churn inevitable?", International Journal of Hospitality Management, Vol. 20 No. 2, pp. 163-185.

Smith, E. (2002), "Training equals staff loyalty at Paramount", Education + Training, Vol. 44 No. 7, pp. 318-319.

"Study highlights benefits of foreign placements for young trainees" (2003), Journal of European Industrial Training, Vol. 27 No. 9, pp. 484-484.

Suutari, V., and Brewster, C. (2001), "Expatriate management practices and perceived relevance: Evidence from Finnish expatriates", Personnel Review, Vol. 30 No. 5, pp. 554-577.

Taylor, R., and Davies, D. (2004), "Aspects of training and remuneration in the accommodation industry: A comparison between Australian and Singaporean providers", Journal of European Industrial Training, Vol. 28 No. 6, pp. 466-473.

Terterov, M. (2004), Doing Business with Kazakhstan, Kogan Page, London.

Timo, N., and Davidson, M. (2005), "A survey of employee relations practices and demographics of MNC chain and domestic luxury hotels in Australia", Employee Relations, Vol. 27 No. 2, pp. 175-192.

Tsang, E. W. K. (1994), "Human Resource Management Problems in Sino-foreign Joint Ventures", International Journal of Manpower, Vol. 15 No. (9/10), pp. 4-21.

Webb, A., and Wright, P. C. (1996), "The expatriate experience: implications for career success", Career Development International, Vol. 1 No. 5, pp. 387-398.

Zhang, H. Q., and Lam, T. (2004), "Human resources issues in the development of tourism in China: evidence from Heilongjiang Province", International Journal of Contemporary Hospitality Management, Vol. 16 No. 1, pp. 45-51. 